\title{
Job Satisfaction among the Healthcare Professionals of Combined Military Hospitals of Bangladesh Munir UR ${ }^{1}$, Rahman $\mathrm{MF}^{2}$, Nosib MNU ${ }^{3}$ \\ DOI: https://doi.org/10.3329/jafmc.v14i2.45900
}

\begin{abstract}
Introduction: Job satisfaction is a cognitive, affective and evaluative reaction towards a job. It is closely linked to an individual's behaviour in the work place. Health Care Professionals of Combined Military Hospitalsface diverse stressful situations while accomplishing their professional commitments. They often concede job satisfaction as a stressor stemming to their work place.
\end{abstract}

Objectives: To findout the Job Satisfaction level among the Healthcare Professionals of $\mathrm{CMH}$ in Bangladesh.

Materials and Methods: A total of 574 respondents were selected from five $\mathrm{CMHs}$ using simple random sampling considering doctors, nurses, paramedic medical assistants and technologists as the study population. The level of job satisfaction was elucidated by certain parameters and occupational stress was measured by Health Professions Stress Inventory.

Results: A high proportion of respondents were found to be satisfied or highly satisfied in regards to work prospects (61.4\%), people they worked with $(86.5 \%)$, physical working conditions $(79.4 \%)$, the way their department was run $(80.7 \%)$, the way their abilities were used (78.2\%) and their interest and skill involved in their job (77.4\%). On the contrary, a marginal majority (56.7\%) were dissatisfied in regards to their salary. $32.4 \%$ were found to be not at all worried about losing their job and more than a half $(60.8 \%)$ mentioned that they feel fairly secured financially for the next 10 years.A significant relationship has been found between job satisfaction and stress $(p<0.05)$.

Conclusion: Professional uniqueness contributes significantly to job satisfaction. Particular improvements in working life can be materialized through scientific planning, maintenance and optimization, valuation of human resources and necessary organizational support.

Key-words: Job Satisfaction, Occupational Stress, Healthcare Professionals, Combined Military Hospitals.

\section{Introduction}

Job satisfaction is a cognitive, affective and evaluative reaction towards a job. It is an emotional response; hence cannot be seen but only be inferred. It is closely linked to an individual's behaviour in the work place; their sense of achievement and success on the job. Job satisfaction has a close relationship with motivation and activity ${ }^{1-3}$. It is impacted by job design, jobs that are rich in positive behavioural elements- such as autonomy, task identity, task significance and feedback contribute to employee's satisfaction. Organizational stress is negatively and significantly related with job satisfaction ${ }^{2}$. Perceived organizational support can lessen the stress level of the employees, thereby indirectly affecting job satisfaction. Employee job performance has always been a major challenge in organizational management and adopting effective ways to motivate employees to achieve and deliver higher job performance as well as increase the organizational competitiveness ${ }^{4-8}$.

There are a variety of factors that can influence an individual's level of job satisfaction. Some of these factors include the level of pay and benefits, the perceived fairness of the promotion system within an organization, the quality of the working conditions, leadership and social relationships, opportunities, advancement and the job itself. It is a key ingredient that leads to recognition and achievement of organizational goal; thereafter lead to a feeling of fulfilment ${ }^{3,8,9}$. Doctors and nurses are the most vulnerable professional groups to occupational stress, as they often encounter stressful situations due to the special demands of their profession. High level of stress is believed to affect the physical and mental health of the health care professionals ${ }^{10-13}$. Combined Military Hospitals provide healthcare to the Armed Forces personnel and their families. As this profession is very sensitive and bears high level of accountability, the doctors, nurses and paramedics face diverse stressful situations while accomplishing their professional commitments. They often admit job satisfaction as a stressor stemming to their workplace. Under such context the current study was designed to assess the parameters of job satisfaction and its significance as a stressor among the health care professionals working in $\mathrm{CMHs}$.

\section{Material and Methods}

This cross sectional study was carried out from July to December 2017. For the purpose of the study four categories of health care professionals: Doctor, Nurse, Paramedic Medical Assistant (PMA) and Paramedic Medical Technologist (PMT) which includes Intensive Care Assistant (ICA), Operation Theatre Assistant (OTA), Laboratory Technician, Special Treatment Assistant (STA), Dental Technician,

1. Col Umar Rashed Munir, MBBS, MPH, MBA, MPhil, Assistant Director Medical Services, 17 Infantry Division, Sylhet (E-mail: umarmunir854@gmail.com) 2. Maj Gen Md Fashiur Rahman, SPP, ndc, MBBS, MPH, LLB, FCGP, MBA, MSS, PhD Fellow, Director General of Medical Services, Bangladesh Armed Forces, Dhaka 3. Maj Md. Nasir Uddin Nosib, MBBS, Graded Specialist in Surgery \& DADGMS (Coord), DGMS, Dhaka. 
Dispenser, Physiotherapist, Radiographer, Sanitary Assistants and Psychiatric Medical Assistants were considered as study population. A total of 574 respondents were selected from five CMH's (Dhaka, Chattogram, Jashore, Bogura and Rangpur. Care was taken to ensure proportional representativeness with the ratio of 1.5: 1: 3.5: 3 for the doctors (97), nurses (65), PMAs (222) and PMTs (190) respectively using simple random sampling. $\mathrm{CMH}$ Dhaka and Chattogram were judgmentally selected as they are larger hospitals. $\mathrm{CMH}$ Jashore was randomly selected between Jashore and Cumilla. Among the other CMH's, Bogura and Rangpur were randomly selected. A pretested self-administered questionnaire was used.

The level of job satisfaction was elucidated by the parameters of salary, work prospects, people work with, physical working condition, and the way department is run, use of ability, interest and skill involved in the job, job security and financial security. These factors were categorized by using a four point Likert scale namely 'very satisfied' to 'very dissatisfied', 'not at all' to 'extremely worried' and 'secure' to 'insecure'11,14,15. Stress was measured by Health Professions Stress Inventory (HPSI) adapted from Alan P Wolfgang, 1998 which comprises 31 items ranging 0 (never) to 4 (very often) that reflects stressful situations frequently encountered by professionals working in the healthcare industry. Higher scores indicate higher levels of job stress with a total score ranging 0-12416. The extent of stress was categorized by using a five point Likert scale 'Not at all stressful (0-0.09)', 'Mildly stressful (0.10-1.00)', 'Moderately stressful (1.10-2.00)', 'Very stressful (2.10-3.00)' and 'Extremely stressful (3.10-4.00). The different degrees of stress- not at all to moderately stressful were further grouped as 'Low' stress and very to extremely stressful were grouped as 'High' stress ${ }^{15,17,18}$. Obtained data were analysed by SPSS21.0for Windows. Univariate and bivariate analysis was carried out using both descriptive and inferential statistics. ANOVA with Post-hoc test, Chi-square test of independence and Fisher's exact test was done to explore association and statistically significant difference. Confidentiality about the participants was strictly maintained.

\section{Results}

In general, $41.1 \%$ health care professionals were in the age group of 26-35 years followed by $35.5 \%$ in the age group of 3645 years (Table-I). The mean work hour per week for doctors, nurses, PMAs and PMTs were 63.25( \pm 18.95$), 55.70( \pm 9.72)$, $89.58( \pm 17.44)$ and $80.58( \pm 16.12)$ hours respectively $(p<0.05)$ (Table-II). Table-III provided information about the parameters of job satisfaction among the health care professionals. A high proportion of respondents were found to be satisfied or highly satisfied in regards to work prospects $(61.4 \%)$, people they worked with $(86.5 \%)$, physical working conditions $(79.4 \%)$, the way their department was run $(80.7 \%)$, the way their abilities were used (78.2) and their interest and skill involved in their job $(77.4 \%)$. On the contrary a marginal majority $(56.7 \%)$ were dissatisfied in regards to their salary. A greater proportion of the respondents admitted that they were mild to moderately worried $(51.8 \%)$ about losing their job, on the other hand $32.4 \%$ were found to be not at all worried. But $15.8 \%$ respondents were identified as very or extremely worried about losing their job (Figure-1). More than a half $(60.8 \%)$ mentioned that they feel fairly secured financially for the next 10 years (Figure-2). About $77.5 \%$ (402) were found to be 'moderately stressful'. Whereas it was identified that $20.7 \%$ (107) respondents were found to be 'very stressful' and $0.8 \%(04)$ as 'extremely stressful' (Figure-3). Around $78.6 \%$ (407) healthcare professionals were in 'low work stress'; whereas $21.4 \%$ (111) were in 'high work stress' category. Statistically significant relationship has been found between job satisfaction and stress $(p<0.001)$ (Table-IV).

Table-l: Distribution of respondents by age and occupation $(n=518)$

\begin{tabular}{|l|c|c|c|c|c|}
\hline \multirow{2}{*}{ Occupation } & \multicolumn{4}{|c|}{ Age groups (in years) } & \multirow{2}{*}{ Mean \pm SD } \\
\cline { 2 - 5 } & $\mathbf{1 6 - 2 5}$ & $\mathbf{2 6 - 3 5}$ & $\mathbf{3 6 - 4 5}$ & $\mathbf{4 6 - 6 2}$ & \\
\hline Doctor (94) & $01(1.1)$ & $43(45.7)$ & $29(30.9)$ & $21(22.3)$ & $38.23 \pm 7.69$ \\
\hline Nurse (64) & $14(21.9)$ & $27(42.2)$ & $21(32.8)$ & $02(3.1)$ & $32.60 \pm 7.10$ \\
\hline PMA (192) & $39(20.3)$ & $91(47.4)$ & $60(31.2)$ & $02(1.0)$ & $32.28 \pm 6.78$ \\
\hline PMT (168) & $37(22.0)$ & $52(31.0)$ & $74(44.0)$ & $05(3.0)$ & $32.94 \pm 8.20$ \\
\hline Total (518) & $91(17.6)$ & $213(41.1)$ & $184(35.5)$ & $30(5.8)$ & $33.62 \pm 7.76$ \\
\hline
\end{tabular}

${ }^{*}$ Percentage in parenthesis

Table-II: Comparison of work hours per week of the respondents by occupational group $(n=518)$

\begin{tabular}{|c|c|c|c|c|c|c|c|}
\hline \multirow{2}{*}{ Occupation } & \multicolumn{5}{|c|}{ Work hour per week } & \multirow{2}{*}{ Mean $\pm S D$} & \multirow{2}{*}{ Statistics } \\
\hline & $\leq 48 \mathrm{hrs}$ & $49-60 \mathrm{hrs}$ & $61-72 \mathrm{hrs}$ & $73-84 \mathrm{hrs}$ & $\geq 85 \mathrm{hrs}$ & & \\
\hline Doctor (94) & $22(23.4)$ & $29(30.9)$ & 18(19.1) & $12(12.8)$ & $13(13.8)$ & $63.25 \pm 18.95$ & \multirow{5}{*}{$\begin{array}{l}\chi^{2}=288.8 \\
d f=12 \\
p \leq 0.001\end{array}$} \\
\hline Nurse(64) & $13(20.3)$ & $41(64.1)$ & $08(12.5)$ & $01(1.6)$ & $01(1.6)$ & $55.70 \pm 9.72$ & \\
\hline & & $08(4.2)$ & & & $97(50.5)$ & 7.44 & \\
\hline & $02(1.2)$ & $13(7.7)$ & $(31.5)$ & $55(32.7)$ & $45(26.8)$ & 16.12 & \\
\hline Total(518) & $37(7.1)$ & $91(17.6)$ & 103(19.9) & $131(25.3)$ & $156(30.1)$ & $77.70 \pm 20.62$ & \\
\hline
\end{tabular}

*Percentage in parenthesis

Table-III: Distribution of respondent's job satisfaction related information $(n=518)$

\begin{tabular}{|l|c|c|c|c|c|}
\hline \multicolumn{1}{|c|}{ Job satisfaction } & $\begin{array}{c}\text { Very } \\
\text { Satisfied }\end{array}$ & Satisfied & Dissatisfied & $\begin{array}{c}\text { Very } \\
\text { Dissatisfied }\end{array}$ & Total \\
\hline Usual Salary & $04(0.8)$ & $220(42.5)$ & $224(43.2)$ & $70(13.5)$ & $518(100)$ \\
\hline Work prospects & $13(2.5)$ & $305(58.9)$ & $153(29.5)$ & $47(09.1)$ & $518(100)$ \\
\hline The people work with & $64(12.4)$ & $384(74.1)$ & $55(10.6)$ & $15(02.9)$ & $518(100)$ \\
\hline $\begin{array}{l}\text { Physical working } \\
\text { conditions }\end{array}$ & $48(09.3)$ & $363(70.1)$ & $85(16.4)$ & $22(04.2)$ & $518(100)$ \\
\hline $\begin{array}{l}\text { The way the } \\
\text { department run }\end{array}$ & $55(10.60$ & $363(70.1)$ & $78(15.1)$ & $22(4.2)$ & $518(100)$ \\
\hline $\begin{array}{l}\text { The way your } \\
\text { abilities are used }\end{array}$ & $56(10.8)$ & $349(67.4)$ & $89(17.2)$ & $24(4.6)$ & $518(100)$ \\
\hline $\begin{array}{l}\text { The interest and skill } \\
\text { involved in your job }\end{array}$ & $54(10.4)$ & $347(67.0)$ & $96(18.5)$ & $21(4.1)$ & $518(100)$ \\
\hline
\end{tabular}

${ }^{*}$ Percentage in parenthesis

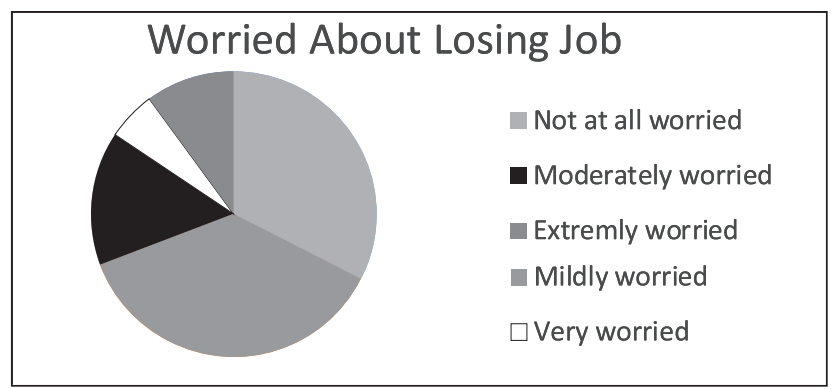

Figure-1: Distribution of respondents' jobsecurity related information $(n=518)$ 


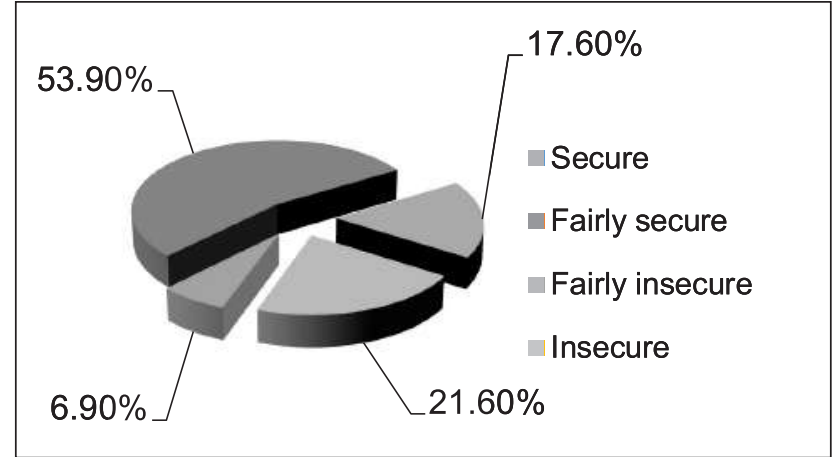

Figure-2: Distribution of respondents by financial security $(n=518)$

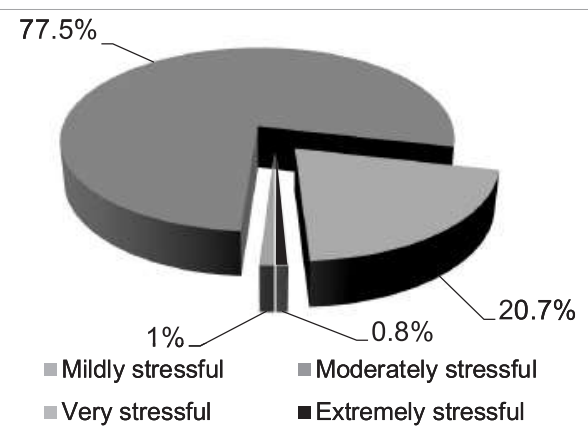

Figure-3: Distribution of respondents by occupational stress measured with HPSI $(n=518)$

Table-IV: Association between respondents' occupational stress and job satisfaction $(n=518)$

\begin{tabular}{|c|c|c|c|c|c|c|}
\hline Job satisfaction & $\begin{array}{c}\text { Very } \\
\text { satisfied }\end{array}$ & Satisfied & Dissatisfied & $\begin{array}{c}\text { Very } \\
\text { dissatisfied }\end{array}$ & Total & Statistics \\
\hline \multicolumn{7}{|l|}{ Usual salary } \\
\hline Low work stress & $03(75.0)$ & $200(90.9)$ & $177(79.0)$ & $27(38.6)$ & $407(78.6)$ & \multirow{2}{*}{$\begin{array}{l}\chi^{2}=86.465 \\
d f=3 \\
p<0.001\end{array}$} \\
\hline High work stress & $01(25.0)$ & $20(9.1)$ & $47(21.0)$ & $43(61.4)$ & $111(21.4)$ & \\
\hline \multicolumn{7}{|l|}{ Work prospects } \\
\hline Low work stress & $12(92.3)$ & $269(88.2)$ & $114(74.5)$ & $12(25.5)$ & $407(78.6)$ & \multirow{2}{*}{$\begin{array}{l}\chi^{2}=98.270 \\
d f=3 \\
p<0.001\end{array}$} \\
\hline High work stress & $01(7.7)$ & $36(11.8)$ & $39(25.5)$ & $35(74.5)$ & $111(21.4)$ & \\
\hline \multicolumn{7}{|l|}{ People work with. } \\
\hline Low work stress & $51(79.7)$ & $331(86.23)$ & $25(45.5)$ & $00(0.0)$ & $407(78.6)$ & \multirow{2}{*}{$\begin{array}{l}x^{2}=104.13 \\
d f=3 \\
p<0.001\end{array}$} \\
\hline High work stress & $13(20.3)$ & $53(13.8)$ & $30(54.5)$ & $15(100.0)$ & $111(21.4)$ & \\
\hline \multicolumn{7}{|c|}{ Physical working conditions. } \\
\hline Low work stress & $42(87.5)$ & $310(85.4)$ & $54(63.5)$ & $01(4.5)$ & $407(78.6)$ & \multirow{2}{*}{$\begin{array}{l}\chi^{2}=95.351 \\
d f=3 \\
p<0.001\end{array}$} \\
\hline High work stress & $06(12.5)$ & $53(14.6)$ & $31(36.5)$ & $21(95.5)$ & $111(21.4)$ & \\
\hline \multicolumn{7}{|c|}{ The way department run. } \\
\hline Low work stress & $48(87.3)$ & $311(85.7)$ & $44(56.4)$ & $04(18.2)$ & 407(78.6) & \multirow{2}{*}{$\begin{array}{l}\chi^{2}=83.757 \\
d f=3 \\
p<0.001\end{array}$} \\
\hline High work stress & $07(12.7)$ & $52(14.3)$ & $34(43.6)$ & $18(81.8)$ & $111(21.4)$ & \\
\hline \multicolumn{7}{|c|}{ The way abilities are used. } \\
\hline Low work stress & $48(85.7)$ & $303(86.8)$ & $50(56.2)$ & $06(25.0)$ & $407(78.6)$ & \multirow{2}{*}{$\begin{array}{l}\chi^{2}=83.211 \\
d f=3 \\
p<0.001\end{array}$} \\
\hline High work stress & $08(14.3)$ & $46(13.2)$ & $39(43.8)$ & $18(75.0)$ & $111(21.4)$ & \\
\hline \multicolumn{7}{|c|}{ The interest and skill involved in job. } \\
\hline Low work stress & $45(83.3)$ & 292(84.1) & $65(67.7)$ & $05(23.8)$ & $407(78.6)$ & \multirow{2}{*}{$\begin{array}{l}x^{2}=51.273 \\
d f=3 \\
p<0.001\end{array}$} \\
\hline High work stress & $09(16.7)$ & $55(15.9)$ & $31(32.3)$ & $16(76.2)$ & $111(21.4)$ & \\
\hline
\end{tabular}

*Percentage in parenthesis

\section{Discussion}

A set of variables were general exploration to rate the job satisfaction of the respondents. A high proportion of respondents were found to be satisfied or highly satisfied in regards to work prospects $(61.4 \%)$, people they worked with $(86.5 \%)$, physical working conditions $(79.4 \%)$, the way their department was run $(80.7 \%)$, the way their abilities were used (78.2) and their interest and skill involved in their job (77.4\%). A marginal majority (56.7\%) were dissatisfied or very dissatisfied in regards to their salary. A study by Mathews ${ }^{19}$ in 2013 revealed that only $7 \%$ of the nurses of Kerala were satisfied with the pay. Similarly, $60 \%$ of the nurses of Maharashtra were not satisfied with their existing salary and benefits, $66 \%$ of the nurses were interested in training for new skills and $60 \%$ desired more training for their present job ${ }^{20}$. Whereas most nurses in the USA were satisfied with their jobs, with $29 \%$ highly satisfied and $64 \%$ generally satisfied with only $7 \%$ dissatisfied ${ }^{21}$. In general, nurses of West Greece reported the most unfavourable psychosocial environment in terms of job satisfaction. A strong negative relationship has been found between nurses' occupational stress and job satisfaction and it has also been reported that growing occupational stress results in increasing turnover rate and causes more and more nurses to leave the nursing profession ${ }^{22}$. A low level of satisfaction was found in Icelandic nurses in regards to salary and opportunities for promotion ${ }^{23}$. Around $60 \%$ pharmacists of Bangladesh and Northern Ireland reported a moderate level of job satisfaction in comparison to $90 \%$ consultant pharmacists of North Carolina ${ }^{24-26}$.

In the current study, it was observed that higher the level of dissatisfaction in regards to the parameters of job satisfaction higher was the prevalence of stress $(p<0.05)$. More than onethird of pharmacy technicians in North Carolina were often/ frequently stressed because of lack of job advancement opportunities, and $60 \%$ because of inadequate pay ${ }^{26}$. The working condition (67.9\%) was found as a source of job stress among Malaysian nurses ${ }^{27}$. Organizational stress was negatively and significantly related to job satisfaction. It could be concluded that health professionals of the regional countries were less satisfied with their pay and benefits in comparison to Europe and United States 6 . A greater proportion of the respondents admitted that they were not at all to moderately worried (84.2\%) about losing their job in the present study. Higher the proportion of feeling worried about losing their job higher was the prevalence of stress $(p<0.05)$. Kane observed among the nurses in Maharashtra that most of them have a permanent employment status; therefore, the stress of job insecurity does not affect them ${ }^{20}$. Many researchers have established job security as a mediator of job satisfaction; absence of which initiates stress ${ }^{28-30}$. The most consistent and significant stressors that distinguished physicians were working for longhours and threat of job loss ${ }^{31}$. 


\section{Conclusion}

Professional uniqueness contributes significantly to job satisfaction with the origination of stress. Both the issues subsidise to the performance of individual as well as the organization. It was outlined that particular improvements in work-life can be materialized through scientific planning, maintenance and optimization, valuation of human resources and necessary organizational support. It is eminent to ensure job satisfaction among the employees with the aim of achieving organizational goal.

\section{References}

1. Tella A, Ayeni CO and Popoola SO. Work motivation, job satisfaction, and organizational commitment of library personnel in academic and research libraries in Oyo State, Nigeria.Library Philosophy and Practice 2007; 4:1-16.

2. Celick M.A theoretical approach to the job satisfaction. Polish Journal of Management Studies 2011; 4:7-15.

3. Aziri B. Job satisfaction: Aliterature review. Management Research and Practice 2011; 3(4):77-86.

4. Rane DB. Employee Job Satisfaction: An Essence of Organization. Indiana University of Pennsylvania publications 2011; 11(7):12-9.

5. Sageer A, Rafat $S$ and Agarwal P. Identification of variables affecting employee satisfaction and their impact on the organization.International Organization of Scientific Research Journal of Business and Management (IOSR-JBM) 2012; 5(1):32-9.

6. Pathak D. Role of perceived organizational support on stresssatisfaction relationship: An empirical study. Asian Journal of Management Research 2012; 3(1):153-77.

7. Raja S and Anand VV. A study on employee job satisfaction with special reference to Krishnagiri district co-operative spinning mills limited. International Research Journal of Business and Management 2013; 2:73-9.

8. Inuwa M. Job Satisfaction and Employee Performance: An Empirical Approach. The Millennium University Journal 2016; 1(1):90-103.

9. Parvin MM and Kabir MMN. Factors affecting employee job satisfaction of pharmaceutical sector. Australian Journal of Business and Management 2011; 1(9):113-9.

10. Berman R, Campbell M, Makin W et al. Occupational stress in palliative medicine, medical oncology and clinical oncology specialist registrars. Clinical Medicine 2007; 7(3):235-42.

11. Westman M, Etzion D and Gortler E. The Work-Family Interface and Burnout. International Journal of Stress Management 2004; 11(4):413-28.
12. Akintayo DI. Work-family role conflict and organizational commitment among industrial workers in Nigeria. Journal of Psychology and Counselling 2010; 2(1):1-8.

13. Arya M and Baroda S. Occupational Stress among Doctors: A Case Study of PT. B. D. Sharma University of Health Sciences Rohtak. Zenith International Journal of Multidisciplinary Research 2012; 2(1):321-8.

14. Jarrod M, Spell HC and O'Driscoll M. Managing work-family conflict: Exploring individual and organisational option. New Zealand Journal of Human Resource Management 2009; 9(3):200-15.

15. Smith A, Johal S, Wordsworth E, Smith GD and Peters T. The scale of occupational stress: The Bristol stress and health at work study (Thesis). Bristol: University of Bristol 2000:265-95.

16. Spooner-Lane R. The influence of work stress and work support on burnout on public hospital nurses (Thesis). Brisbane: Queensland University of Technology; 2004:198-215.

17. Daud $S$, Kashif $R$ and Shuja $H$. Stress in medical educators. Professional Medicine Journal 2012; 19(3):404-10.

18. Sayed HY and Ibrahim MM. Stressors among nursing staff working in intensive care unit in governmental and non-governmental hospitals at Makkah Al-Moukarramah, KSA. Journal of American Science 2012; 8(6):1-7.

19. Mathew AN. Effect of stress on job satisfaction among nurses in Central Kerala.International Organization of scientific ResearchJournal of Business and Management 2013; 7(2):47-51.

20. Kane PP. Stress causing psychosomatic illness among nurses. Indian Journal of Occupational and Environmental Medicine 2009; 13(1):28-32.

21. Letvak $S$ and Buck R. Factors Influencing Work Productivity and Intent to Stay in Nursing. Nursing Economics 2008; 26(3):159-65.

22. Jelastopulu $E$, Tsouvaltzidou $T$, vangeli $E$ et al. Selfreported sources of stress, job satisfaction and quality of care in professional hospital nurses in West-Greece. Nursing and Health 2013; 1(1):1-9.

23. Sveinsdottir H, Biering $P$ and Ramel A. Occupational stress, job satisfaction, and working environment among Icelandic nurses: A cross-sectional questionnaire survey.International Journal for Nursing Studies 2006; 43(7):875-89.

24. McCann L, Hughes CM, Adair CG and Cardwell C. Assessing job satisfaction and stress among pharmacists in Northern Ireland. Pharmacist World Science 2009; 31:188-94.

25. Parvin MM and Kabir MMN. Factors affecting employee job satisfaction of pharmaceutical sector.Australian Journal of Business and Management Research 2011; 1(9):113-23. 
26. Lapane $\mathrm{KL}$ and Hughes $\mathrm{CM}$. Baseline job satisfaction and stress among pharmacists and pharmacy technicians participating in the Fleetwood phase III study. The Consultant Pharmacist 2004; 19(11):1029-37.

27. Loo-See B and Leap-Han L. Job stress and coping mechanisms among nursing staff in public health services.International Journal of Academic Research in Business and Social Sciences 2012; 2(7):131-76.

28. Islam MN. A relational study on organizational commitment, career satisfaction, job involvement, job security, and job satisfaction in the context of social investment bank limited (Thesis). Independent University, Bangladesh; 2006.
29. Jeon J. The impact of organizational justice and job security on organizational commitment exploring the mediating effect of trust in top management (Thesis). University of Minnesota, Minneapolis, United States, 2009.

30. Bosman J, Buitendach JH andLaba K. Job insecurity, burnout and organizational commitment among employees of a financial institution in Gauteng. South African Journal of Industrial Psychology 2005; 31(4):32-40.

31. Belkic $K$ and Savic $C$. The occupational stress index- an approach derived from cognitive ergonomics applicable to clinical practice. Scandinavian Journal of Work Environment and Health 2008; 6:169-76. 